\title{
ДИНАМИКА ЭКЗОГЕННЫХ ПРОЦЕССОВ НА УЧАСТКАХ СТРОИТЕЛЬСТВА ОБЪЕКТОВ СПОРТИВНО-ТУРИСТИЧЕСКОГО КОМПЛЕКСА «ГОРНЫЙ ВОЗДУХ»
}

\author{
Сахаров Валерий Александрович', \\ sakhsakh@yandex.ru \\ Ильин Владимир Вениаминович', \\ vladimirilyin7@gmail.com \\ 1 Сахалинский государственный университет, \\ Россия, 693008, г. Южно-Сахалинск, ул. Ленина, 290.
}

Актуальность исследования обусловлена необходимостью обеспечения безопасности строительства и эксплуатации объектов Спортивно-туристического комплекса «Горный воздух» в г. Южно-Сахалинске.

Цель: обнаружение признаков активизации экзогенных геологических процессов во время строительства объектов СТК «Горный воздух», оценка их опасности, изучение влияния на водные объекты.

Объекты: территории под канатными дорогами, горнолыжные трассы, площадки строительства зданий и сооружений инфраструктуры объекта и технологические дороги на северном и южном склонах г. Большевик, водохранилище на р. Рогатка, водозабор на р. Еланька.

Методы: изучение результатов инженерных изысканий, выполненных различными организациями на склонах горы Большевик; изучение режима эксплуатации водозаборов на реках Еланька и Рогатка; полевое обследование объектов СТК «Горный воздух» на склонах г. Большевик; отбор проб воды из водных объектов на химические анализы.

Результаты. На территориях под канатными дорогами и вновь построенных горнолыжных трасс наблюдается обнаженный грунт, местами до зоны экзогенной трещиноватости и коренных пород. В кабельных траншеях наблюдаются незначительные просадки насыпного грунта, обусловленные гравитационным уплотнением и суффозионными процессами. Отмечаются следы водной эрозии грунта. Признаков оползневой и селевой активности не наблюдается. Ручьи, стекающие по склонам, прозрачные. Строительные работы в долине реки Еланьки влияют только на продолжительность перерывов в эксплуатации водозабора. Влияние строительства объектов спортивно-туристического комплекса на качество воды в водохранилище на р. Рогатка не установлено, режим работы водозабора на водохранилище не изменялся.

\section{Ключевые слова:}

Экзогенные процессы, оползневые процессы, селевые процессы, суффозия, водохранилище, грунтовые воды, водозабор.

\section{Введение}

Строительство в горной местности нередко приводит к нарушению природного равновесия и активизации склоновых процессов. Обеспечение безопасности во время строительства и эксплуатации объектов - приоритетная задача инженерных изысканий [1-6]. Недоучет или неправильный прогноз возможных последствий изменения инженерно-геологических условий могут привести к негативным результатам. Вместе с тем необоснованный (некомпетентный, преднамеренный) «катастрофизм» также оказывает отрицательное влияние, выраженное в затягивании процесса строительства и различного рода разбирательствах.

Учитывая высокую социальную значимость поднимаемых вопросов, выполнены исследования по оценке степени активизации экзогенных процессов на участках строительства СТК «Горный воздух», отмеченных в обращениях граждан, и их влияние на водные объекты. Работы выполнены весной-летом 2017 г. и весной 2018 г. (результаты получены в рамках выполнения государственного задания Минобрнауки РФ: 5.9560.2017/8.9).

Исходныли данныли для проведения исследований являлись технические отчеты о результатах инженерных изысканий для строительства отдельных объектов СТК; сведения о климате, гидрографической сети, рельефе, геоморфологии, особенно- стях геологического строения, гидрогеологических условиях, геологических и инженерно-геологических процессах, физико-механических свойствах грунтов, техногенных воздействиях на окружающую среду, отраженные в опубликованной литературе [7-11]. Также было оценено современное состояние изучения склоновых процессов в научно-исследовательской литературе [12-20].

На основании анализа материалов была составлена программа исследований.

Полевое обследование объектов «СТК «Горный воздух» на склонах г. Большевик проводилось путем пеших маршрутов. Маршруты выполнены в начале мая, в период интенсивного снеготаяния, и в июне, после окончания половодья (2017 г.). В мае 2018 г. проведено повторное обследование тех же объектов, в том числе: горнолыжных трасс «Север», «Восток», «Юг», «Серпантин»; территорий под канатными дорогами «Север», «Юг»; территорий нижних станций канатных дорог «Север», «Юг»; грунтовой дороги по правому берегу p. Еланька от ул. Больничной до нижней станции канатной дороги «Юг»; технологической дороги от пер. Алтайский до нижней станции канатной дороги «Север» (рис. 1).

В ходе выполнения маршрутов, велись наблюдения за развитием экзогенных процессов и состоянием водотоков. 


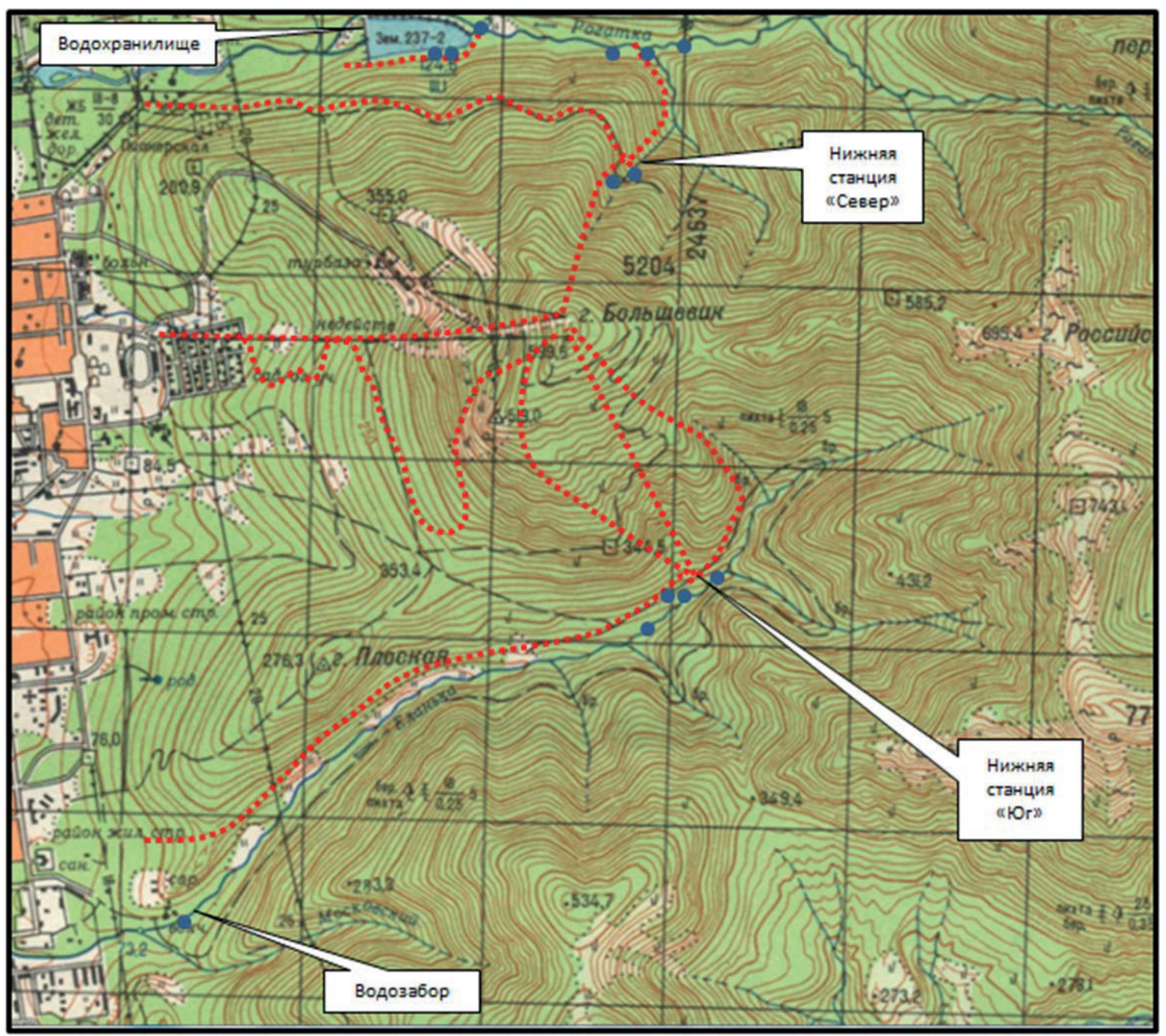

(длина стороны квадрата на схеме соответствует 1 км)

\section{...*. Маршрут инженерно-геологического обследования}

\section{- Точка отбора пробы воды на химический анализ}

Pис.1. Схема расположения участков исследований

Fig. 1. Scheme of location of the sites

\section{Результаты обследований}

Грунтовая дорога от ул. Больничной до нижней станции канатной дороги «Юг» проходит по правому берегу р. Еланька, русло реки не пересекает. Обследование дороги пешим обходом, выполненное в мае 2017 и 2018 гг., показало, что сток мутной воды с дороги в реку Еланька отсутствует, признаков оползневой и селевой опасности не отмечено.

Обследование технологической дороги от пер. Алтайского до нижней станции канатной дороги «Север» выполнено 5 мая 2017 г. В ходе обследования признаков оползневой и селевой активности не наблюдалось. Ручьи, стекающие с горы, прозрачные - взвешенные вещества (ВВ) 111,4 мг/дм³ . Под дорогой ручьи пропущены по трубам, после прохождения по которым прозрачность воды не изменяется. При повторном обследовании через год, в мае 2018 г., каких-либо изменений не отмечено.

На склонах, примыкающих к дорогам, имеют незначительное развитие следующие процессы.

Оползень вязкопластический (оплывина) (пример: 3-й километр дороги от ул. Больничной) образовался в месте концентрирования подземных вод в микропонижениях рельефа, что обусловило развитие суффозионных процессов и как след- 
ствие - проявление гидрогенного крипа с образованием мочажин. Сформировался ориентировочно 40-50 лет назад, судя по возрасту деревьев. Глубина захвата контролируется границей перехода от суглинистых грунтов к щебенистым в делювиальных отложениях и составляет от 0,7 до 0,9 м. Размеры оплывины достигают $20 \times 40$ м. Состояние оплывины устойчивое, коэффициент устойчивости $K_{\mathrm{y}}=7,0$ (рис. 2).

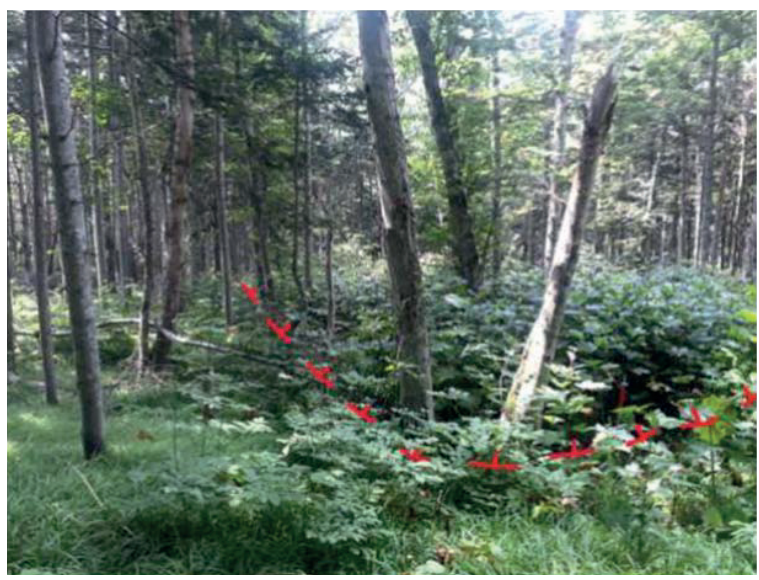

Pис. 2. Оползень вязкопластический (опльвина)

Fig. 2. Land slide viscoplastic (olivine)

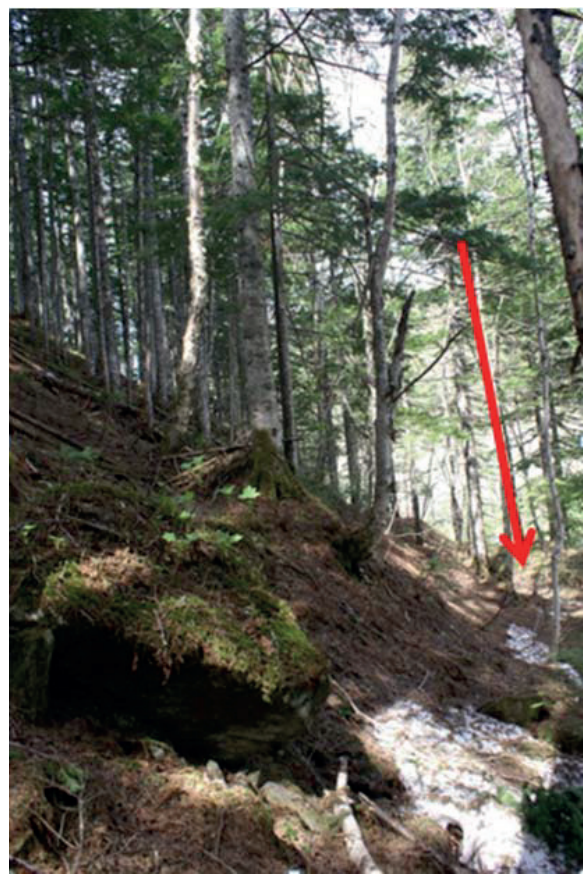

Pис. 3. Оползень внезапного (сейслогенного) разжижения

Fig. 3. Land slide of sudden (seismic) liquefaction

Оползень внезапного (сейсмогенного) разжижения - смещение горных масс в виде уступов, достигающих одного метра по вертикали. Глубина захвата составляет 0,5-0,9 м. Наблюдаемые размеры $60 \times 40$ м. Состояние горных пород устойчивое возраст деревьев на поверхности оползневого тела составляет несколько десятков лет, деревья прямо- стоящие. Коэффициент устойчивости $K_{\mathrm{y}}=3,1$. Склон устойчив (рис. 3).

В местах подреза склонов наблюдаются оползни гидродинамического разрушения (суффозионные) - идентифицируются как развитие комплексного крипа по саблевидному состоянию стволов деревьев. Процесс развивается медленно - возраст деревьев не менее 40 лет (рис. 3, 4).

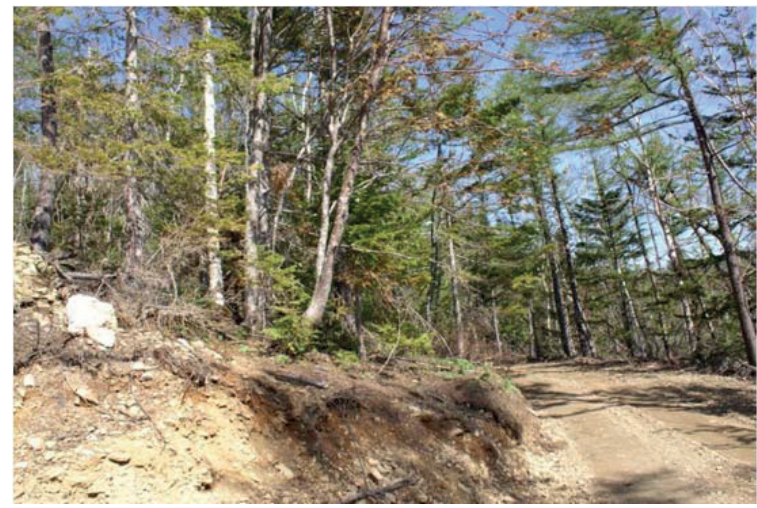

Рис. 4. Оползни гидродинамического разрушения

Fig. 4. Land slides of hydrodynamic destruction

Нижняя станция канатной дороги «Юг» (5 мая 2017 г.). Территория отсыпана строительным грунтом, неоднородным по гранулометрическому составу (рис. 5). Ручьи, стекающие с горы, инфильтруются в грунт. Местами наблюдаются просадки линейной формы, обусловленные механической суффозией по направлению движения подземных вод. Рассредоточенная разгрузка подземных вод в русло реки Еланьки не вызывает замутнения воды в реке.

В южной части территории станции ширина насыпного грунта сокращается до 5-7 м (рис. 6). В том же месте наблюдается выход ручья с расходом 5 л/с (половодье), вода в ручье прозрачная. По состоянию на 05.05.2017 г. ручей фильтровался в тело грунтового отвала и выходил с противоположной стороны. В связи с достаточно высоким гидродинамическим уклоном происходил интенсивный вынос частиц грунта глинистой и пылеватой фракций. Вода, выходившая из грунтового тела, мутная.

Вымывание мелкодисперсных частиц происходило довольно быстро - 20 мая 2017 г. наблюдается провал кровли грунтового отвала в месте инфильтрации ручья, вода в ручье прозрачная. К 27 июля 2017 г. сформировалось новое русло ручья. Через год значительных изменений в морфологии грунтового отвала не наблюдается, что свидетельствует о его стабилизации.

С точки зрения возможного формирования оползня или селя грунтовый массив опасности не представляет.

5 мая 2017 г. (половодье) вода в реке Еланька ниже по течению от нижней станции «Юг» замутненная из-за привнесения ручьем обломочного материала (BВ) - 440 мг/дм³ ${ }^{3}$. 23 мая 2018 г. (поло- 

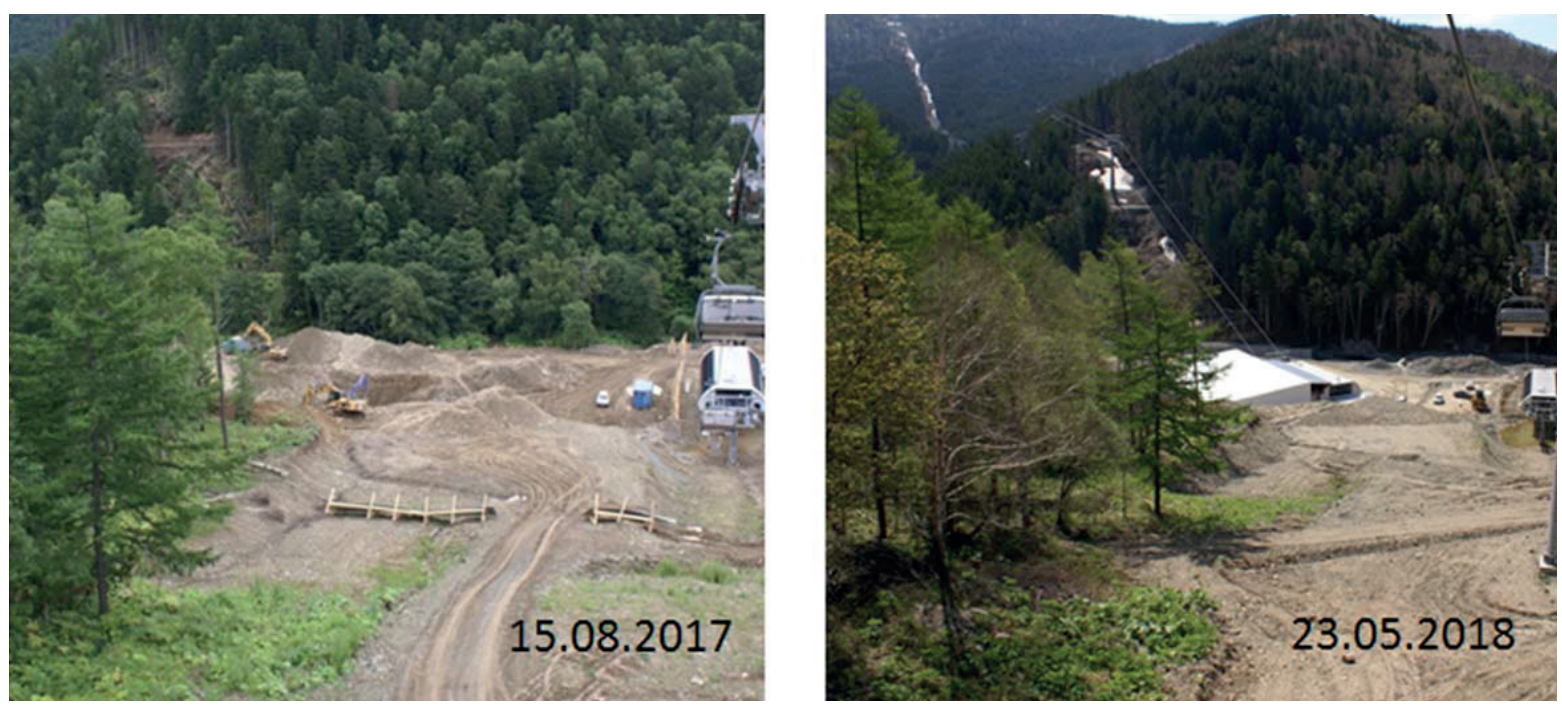

Puс. 5. Вид на нижнюю станцию «Юг»

Fig. 5. View of the lower station «Yug»

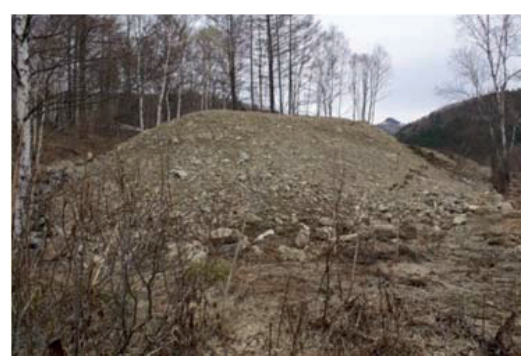

05.05 .2017

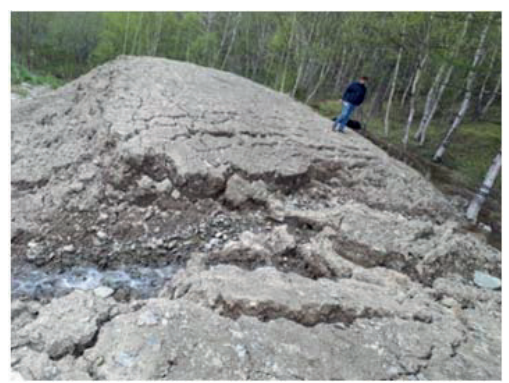

20.05.2017

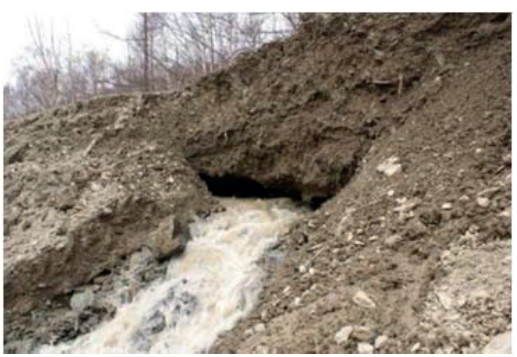

05.05 .2017

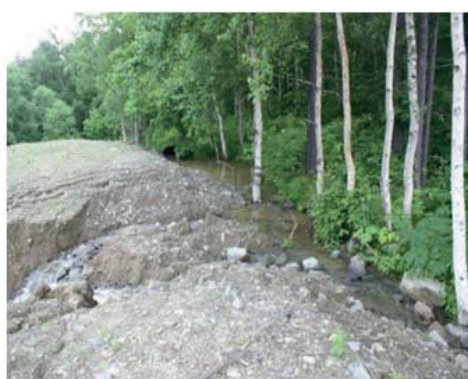

27.07.2017

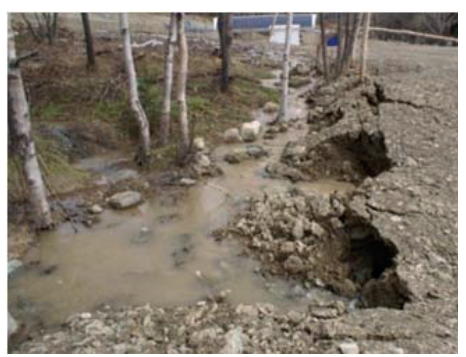

05.05.2017

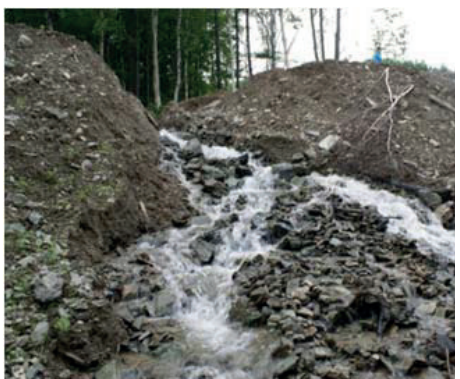

27.07.2017

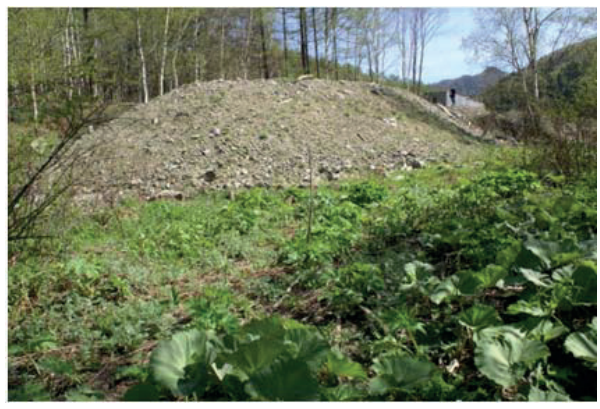

23.05.2018

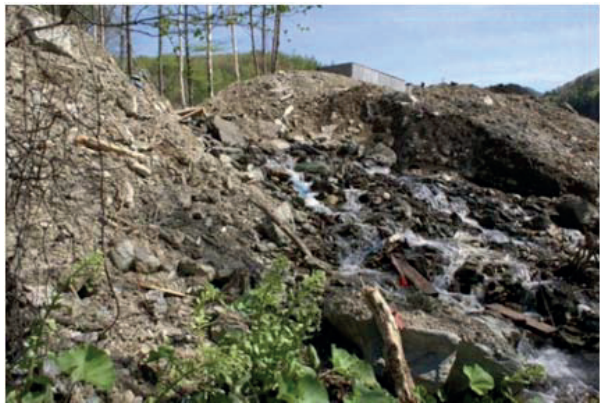

23.05.2018

Рис. 6. Диналика стабилизации грунтового отвала в южной части площадки нижней станции канатной дороги «Юг»

Fig. 6. Dynamics of soil dump stabilization in the southern part of the lower platform «Yug» cablecar station 


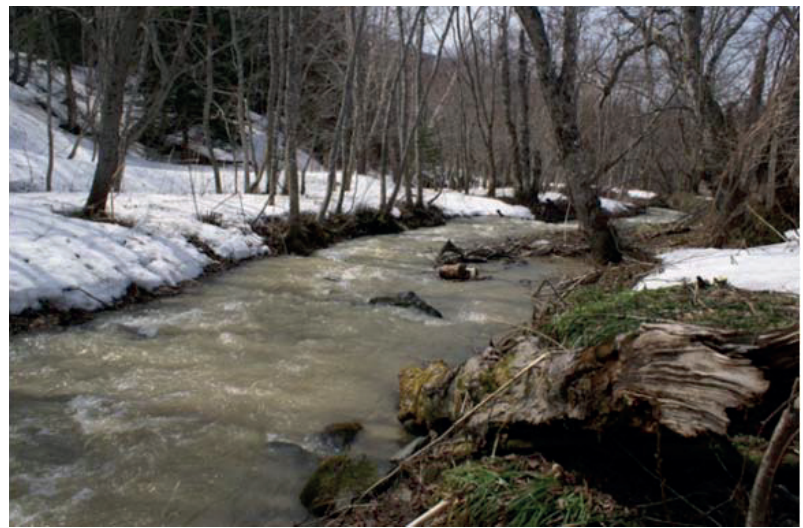

05.05.2017

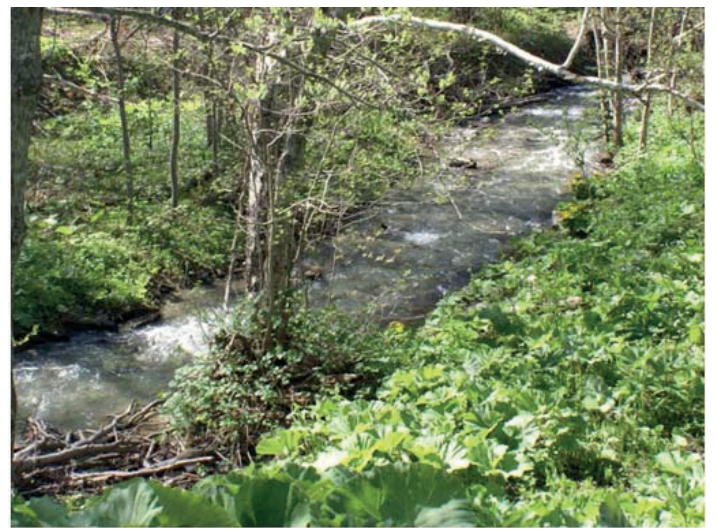

23.05.2018

Рис. 7. Русло реки Еланьки ниже по течению нижней станции канатной дороги «Юг»

Fig. 7. Elanka riverbed downstream the lower station of the cableway «Yug»

водье) вода на том же отрезке реки прозрачная, что свидетельствует о затухающем характере влияния строительных работ на водные объекты (рис. 7).

На выходе в долину 05.05.2017 г., в месте расположения водозабора на реке Еланька (рис. 1), концентрация взвешенных веществ несколько повышается (ВВ - 660 мг/дм $\left.{ }^{3}\right)$.

Результаты химических анализов проб воды, отобранных из реки Еланька выше и ниже впадения ручья, выходящего из грунтового отвала и из самого ручья, показывают, что химического загрязнения речных вод не происходит. Влияние строительных работ выражается только в механическом сносе тонкодисперсных частиц в водотоки и, соответственно, повышении концентрации взвешенных веществ в воде.

Нижняя станция канатной дороги «Север». 05 мая 2017 г. на территории наблюдается обнаженный грунт, местами до коренных пород. Отмечаются незначительные следы водной эрозии грунта, обусловленной вымыванием частиц глинистой и пылеватой фракций. Признаков оползневой активности не наблюдается (рис. 8).

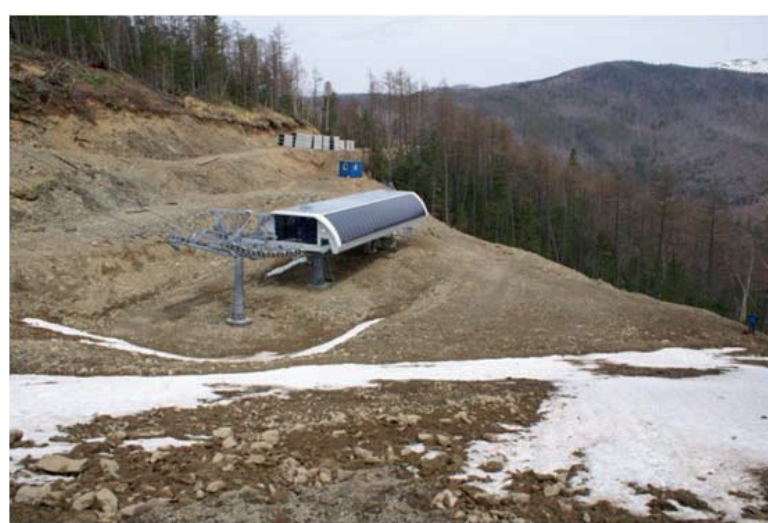

05.05 .2017
На северной оконечности территория площадки увеличена за счет искусственной насыпи. В месте сочленения естественных и техногенных грунтов наблюдаются трещины оседания протяженностью на всю длину сочленения, ширина до 30 см. Образование трещин обусловлено процессами гравитационного уплотнения грунта и суффозией. В 2018 г. трещины не наблюдаются (рис. 9), что, очевидно, обусловлено стабилизацией грунтовой насыпи.

Выше станции горнолыжную трассу пересекают два ручья. Расход в нижнем ручье $-0,5$ л/с. Вода опалесцирует (ВВ - 328 мг/дм³, 05 мая 2017 г.). В верхнем ручье расход $-2,0$ л/с. Вода сильно замутнена (ВВ - более $5000 \mathrm{мг} /$ дм$\left.^{3}\right)$.

В нижней части площадки ручьи сливаются в один. Далее вода по распадку уходит в русло р. Рогатка (рис. 10).

Для оценки влияния ручья, стекающего с нижней станции "Север» (рис. 10), на качество воды в р. Рогатка были отобраны пробы воды из ручья в его устье и из реки Рогатка выше и ниже устья ручья. Результаты химических анализов свидетельствуют о том, что вода из ручья, даже в период ин-

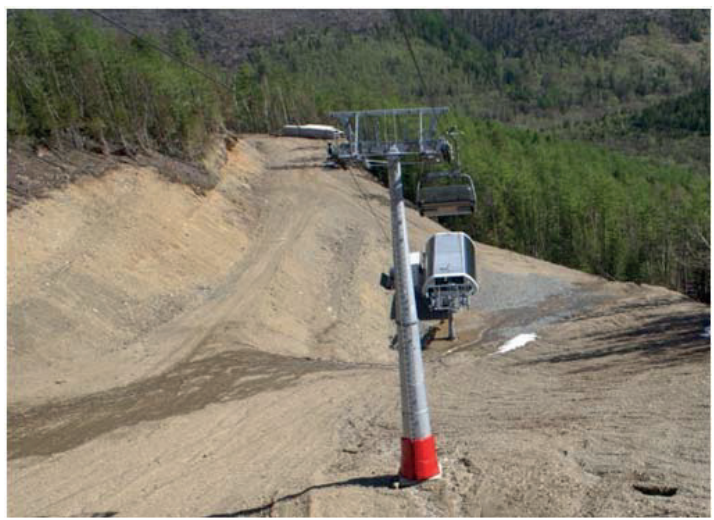

23.05.2018

Puс. 8. Площадка нижней санции канатной дороги «Север»

Fig. 8. Platform of the lower station of the cable car «Sever» 


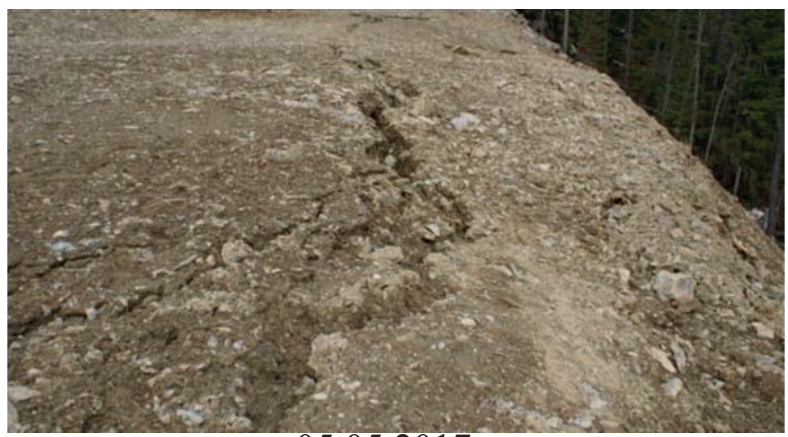

05.05 .2017

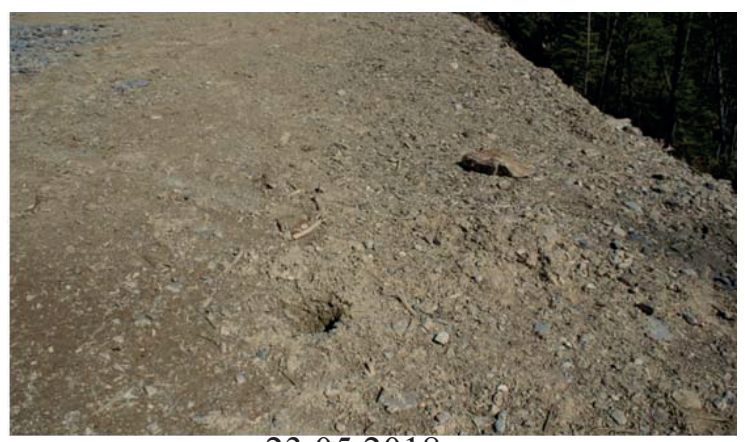

23.05 .2018

Рис. 9. Трещины оседания

Fig. 9. Subsidence cracks

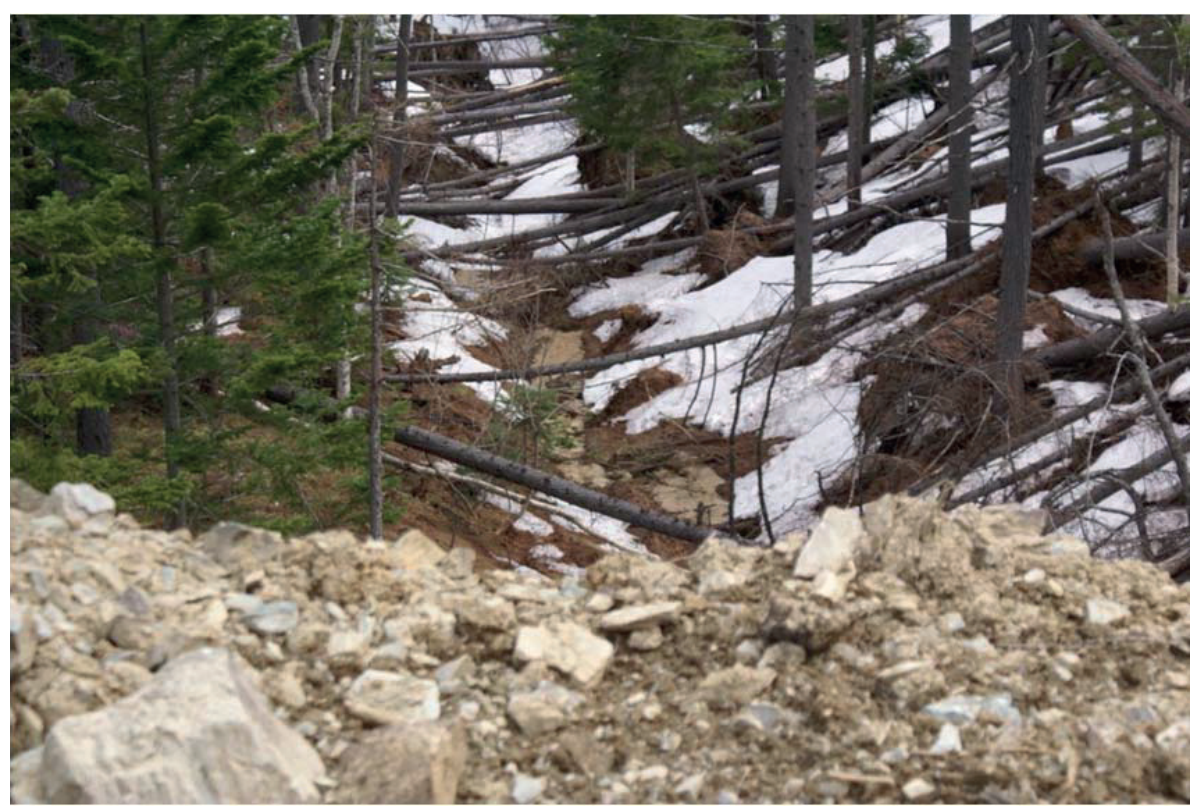

Pис. 10. Ручей ниже станции канатной дороги «Север»

Fig. 10. Stream below the cable car station «Sever»

тенсивного паводка, не оказывает существенного влияния на качество воды в реке Рогатка. Концентрация взвешенных веществ в ручье $-20 \mathrm{мг} /$ дм $^{3}$, в p. Рогатка выше по течению от устья ручья $22 \mathrm{мг} /$ дм $^{3}$, ниже по течению - $19 \mathrm{мг} /$ дм $^{3}$.

На территориях под канатными дорогами и вновь построенных горнолыжных трасс наблюдается обнаженный грунт, местами до зоны экзогенной трещиноватости и коренных пород. В кабельных траншеях наблюдаются незначительные просадки насыпного грунта, обусловленные гравитационным уплотнением и суффозионными процессами (рис. 11).

Отмечаются следы водной эрозии грунта. Признаков оползневой и селевой активности не наблюдается. Ручьи, стекающие по склонам, прозрачные.

Обследование южного берега водохранилища на р. Рогатке. Обследование выполнено пешим маршрутом с Запада на Восток (рис. 1). В ходе выполнения маршрута обнаружены два ручья. В первом ручье вода опалесцирует, расход составляет 3-4 л/с, концентрация взвешенных веществ
$137 \mathrm{мг} /$ дм³ $^{3}$. Во втором ручье вода прозрачная, кон-

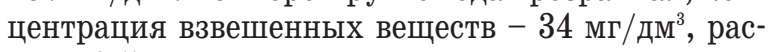
ход - 0,5 л/с. По органолептическим свойствам вода не отличается от воды в ручьях, не пересекающих зону строительства.

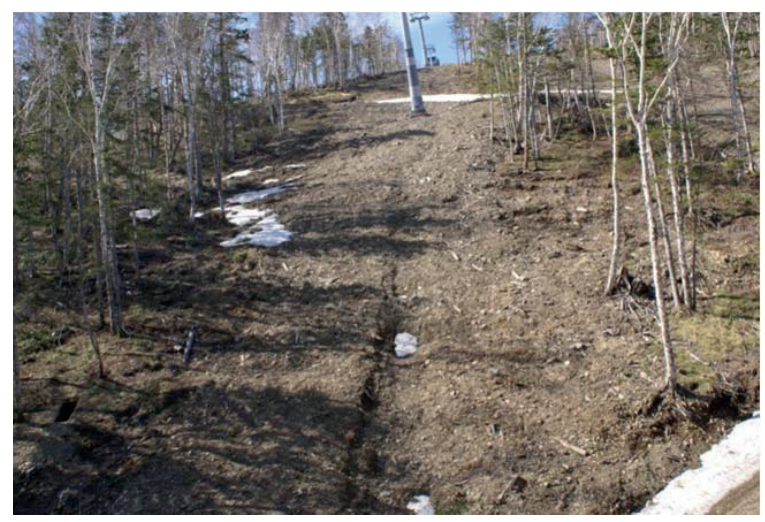

Рис. 11. Просадки грунта в кабельной канаве

Fig. 11. Soil subsidence in the cable ditch 
Концентрация взвешенных веществ в р. Рогатка в районе верхнего шибера - $180 \mathrm{мг} /$ дм³ $^{3}$.

Водохранилище на р. Рогатка. Емкость 560 тыс. $\mathbf{M}^{3}$. Используется для хозяйственно-питьевого водоснабжения южной части города. Расход воды - до 20 тыс. $\mathrm{m}^{3} /$ сут. Не является основным для города. В паводковые периоды, когда наблюдается повышение концентрации взвешенных веществ, верхний шибер водохранилища перекрывается. Водоснабжение осуществляется за счет накопленной воды. Влияние строительства СТК на качество воды в водохранилище не установлено. Режим эксплуатации водохранилища после начала строительных работ не изменился.

Водозабор на р. Еланька расположен в месте выхода реки в долину (рис. 1). Водозабор инфильтрационного типа - вода из русла реки через песчаные фильтры поступает в накопитель для дальнейшей обработки. Используется для водоснабжения юго-восточных районов г. Южно-Сахалинска. Расход воды - до 5 тыс. $\mathbf{m}^{3} /$ сут. Не является основным для города. В паводковые периоды, когда наблюдается повышение концентрации взвешенных веществ, с целью экономии фильтрующего материала водозабор не эксплуатируется. Недостаток воды компенсируется полностью за счет других водозаборов. Строительные работы в долине реки Елань-

\section{СПИСОК ЛИТЕРАТУРЫ}

1. Landslide management in the UK - the problem of managing hazards in a "low-risk» environment / A.D. Gibson, M.G. Culshaw, C. Dashwood, C.V.L. Pennington // Landslides. - 2013. V. 10 (5). - P. 599-610.

2. Mulargia F., Visconti G., Geller R.J. Scientific principles and public policy // Earth-Science Review. - 2018. - V. 176. P. 214-221.

3. Geometrical characteristics of earthquake-induced landslides and correlations with control factors: a case study of the 2013 Minxian, Gansu, China, Mw 5.9 event / Y. Tian, C. Xu, J. Chen, Q. Zhou, L. Shen // Landslides. - 2017. - V. 14 (6). P. $1915-1927$.

4. Coupling fluvial processes and landslide distribution toward geomorphological hazard assessment: a case study in a transient landscape in Japan / C-Y. Tsou, M. Chigira, Y. Matsushi, N. Hiraishi, N. Arai // Landslides. - 2017. - V. 14 (6). - P. 1901-1914.

5. Walsby J.C. Geosure: a bridge between geology and decision making // Communicating Environmental Geoscience. - London, UK: Geological Society, 2008. - P. 81-87.

6. Конюшков В.В., Веселов А.А., Кондратьева Л.Н. Комплексный анализ результатов инженерных изысканий для проектирования, строительства и эксплуатации сооружений на территориях со склоновыми процессами // Известия Томского политехнического университета. Инжиниринг георесурсов. 2017. - T. 328. - № 11. - С. 111-125.

7. Водный кадастр СССР. Многолетние данные о режиме поверхностных вод суши. Бассейны рек Сахалинской области / под ред. Ж.А. Чернышовой. - Л.: Гидрометиздат, 1987. - Т. 1. Вып. 22. - 228 c.

8. Геология СССР. Т. XXXIII. Остров Сахалин / под ред. А.В. Сидоренко. - М.: Недра, 1970. - 431 с.

9. Гидрогеология СCCP. T. XXIV. Остров Сахалин / под ред. А.В. Сидоренко. - М.: Недра, 1972. - 344 с. ки влияют только на продолжительность перерывов в эксплуатации водозабора, т. к. полностью исключить влияние работ невозможно. По данным МКП «Городской Водоканал», перерыв в работе водозабора в половодье (апрель-май) 2016 г. составил 19 суток, 2017 г. - 42 суток.

\section{Заключение}

Динамика экзогенных процессов при строительстве объектов СТК «Горный воздух» на склонах горы Большевик в целом соответствует природным условиям местности. На участках, где снят дерновый покров или складировали рыхлый строительный грунт, происходит вымывание тонкодисперсных частиц, что, в свою очередь, приводит к повышению концентрации взвешенных веществ в водотоках, других изменений химического состава воды в реках и ручьях не происходит. Существенного влияния на водоснабжение города строительные работы не оказывают. На обнаженных склонах отмечаются незначительные проявления эрозионных и суффозионных процессов. В связи с небольшой мощностью делювиальных и элювиальных отложений перечисленные процессы довольно быстро затухают. Признаков активизации оползневых и селевых процессов не наблюдается.

10. Результаты исследований природных условий и инженерногеологического строения долины реки Большая Александровка (о. Сахалин) / В.А. Мелкий, В.В. Ильин, В.М. Пищальник, В.А. Сахаров и др. // Известия Томского политехнического университета. Инжиниринг георесурсов. - 2015. - Т. 326. № 11. - С. 6-20.

11. Научно-прикладной справочник по климату СССР. Многолетние данные. Сахалинская область / под ред. Е.П. Борисенкова. - Л.: Гидрометеоиздат.- 1990. - Сер. 3. - Ч. 1-6. - Вып. 34. - 351 с.

12. Dugdale S.J., Hannah D.M., Malcolm I.A. River temperature modelling: a review of process-based approaches and future directions // Earth-Science Reviews. - 2017. - V. 175. - P. 97-113.

13. Geomorphology on geologic timescales: Evolution of the late Cenozoic Pacific paleosurface in Northern Chile and Southern Peru / L.A. Evenstar, A.E. Mather, A.J. Hartley, F.M. Stuart, F.J. Cooper // Earth-Science Review. - 2017. - V. 171. - P. 1-127.

14. Effects of bedrock anisotropy on hillslope failure in the Darjeeling-Sikkim Himalaya: an insight from physical and numerical models / S. Roy, A. Baruah, S. Misra, N. Mandal / Landslides. 2015. - V. 12 (5). - P. 927-941.

15. Stewart L.S., Lewis D. Communicating contested geoscience to the public: Moving from «matters of fact» to "matters of concern» // Earth-Science Reviews. - 2017. - V. 174. - P. 122-133.

16. Дудлер И.В., Хайме Н.М., Лярский С.П. Методология инженерных изысканий для особо опасных, технически сложных и уникальных объектов // Геоэкология. Инженерная геология. Гидрогеология. Геокриология. - 2013.- Т. 2. - С. 115-129.

17. Семикина С.С., Сотников П.В. Оценка оползневой опасности береговых склонов на территории города Барнаул // Известия Томского политехнического университета. Инжиниринг георесурсов. - 2017. - Т. 328. - № 7. - С. 67-75.

18. Strokova L.A. Methods of estimating surface settlement during driving of urban tunnels // Soil Mechanics and Foundation Engineering. - 2010. - V. 47. - № 3. - P. 92-95. 
19. Strokova L.A., Ermolaeva A.V., Golubeva V.V. The Investigation of Dangerous Geological Processes Resulting In Land Subsidence While Designing the Main Gas Pipeline in South Yakutia // IOP Conference Series: Earth and Environmental Science. - 2016. № $43 .-6 \mathrm{p}$.
20. Zogning A., Ngouanet C., Tiafack 0. The catastrophic geomorphological processes in humid tropical Africa: A case study of the recent landslide disasters in Cameroon // Sedimentary Geology. - 2007. - V. 199. - P. 13-27.

Поступила 16.10.2018 2.

\section{Информация об авторах}

Сахаров В.А., кандидат геолого-минералогических наук, заведующий лабораторией Сахалинского государственного университета.

Ильин В.В., старший преподаватель кафедры строительства Технического нефтегазового института Сахалинского государственного университета. 
UDC 551.4.04

\title{
DYNAMICS OF EXOGENOUS PROCESSES AT AREAS OF CONSTRUCTING THE OBJECTS OF TOURISTIC COMPLEX «GORNY VOZDUKH»
}

\author{
Valeriy A. Sakharov', \\ sakhsakh@yandex.ru \\ Vladimir V. Ilin', \\ vladimirilyin7@gmail.com \\ 1 Sakhalin State University, \\ 290, Lenin street, Yuzhno-Sakhalinsk, 693008, Russia.
}

The relevance of the research is caused by the need to ensure the safety of construction and operation of the facilities of the Sport and Tourism Complex "Gorny vozdukh» in Yuzhno-Sakhalinsk.

The aim of the research is to detect the signs of activation of exogenous geological processes while constructing the facilities of the Sport and Tourism Complex "Gorny vozdukh», to assess their danger and study their influence on water bodies.

Objects: the territory under cable cars, ski slopes, buildings and constructions of the infrastructure and technological roads on the northern and southern slopes of Bolshevik, reservoir on the river Rogatka, water intake on the river Yelanka.

Methods: study of the results of engineering surveys carried out by various organizations on the slopes of Bolshevik Mountain; investigation of the operation mode of water intakes on the Yelanka and Rogatka rivers; field survey of the facilities of the Sport and Tourism Complex "Gorny vozdukh» on the slopes of Bolshevik; sampling of water from water bodies for chemical analyzes.

Results. In the territories under cableways and newly built ski slopes, bare ground is observed, in places up to the zone of exogenous fissuring and bedrock. In cable trenches there are insignificant drawdowns of bulk ground, caused by gravity densification and suffosion processes. Traces of water erosion are noted. There are no signs of landslide and mudflow activity. Brooks flowing down the slopes are transparent. Construction works in the valley of the Yelanka River affect only the duration of breaks in the operation of the water intake. The influence of the Sport and Tourism Complex construction on water quality in the reservoir on the river Rogatka is not established, the operation mode of the water intake in the reservoir has not changed.

Key words:

Soil erosion, landslides, mudflow, suffusion, reservoir, ground water, water intake.

\section{REFERENCES}

1. Gibson A.D., Culshaw M.G., Dashwood C., Pennington C. V.L. Landslide management in the UK - the problem of managing hazards in a «low-risk» environment. Landslides, 2013, vol. 10 (5), pp. 599-610.

2. Mulargia F., Visconti G., Geller R.J. Scientific principles and public policy. Earth-Science Review, 2018, vol. 176, pp. 214-221.

3. Tian Y., Xu C., Chen J., Zhou Q., Shen L. Geometrical characteristics of earthquake-induced landslides and correlations with control factors: a case study of the 2013 Minxian, Gansu, China, Mw 5.9 event. Landslides, 2017, vol. 14 (6), pp. 1915-1927.

4. Tsou C-Y., Chigira M., Matsushi Y., Hiraishi N., Arai N. Coupling fluvial processes and landslide distribution toward gemorphological hazard assessment: a case study in a transient landscape in Japan. Landslides, 2017, vol. 14 (6), pp. 1901-1914.

5. Walsby J.C. Geosure: a bridge between geology and decision making. Communicating Environmental Geoscience. London, UK, Geological Society, 2008. pp. 81-87.

6. Konyushkov V.V., Veselov A.A., Kondratyeva L.N. Comprehensive analysis of engineering survey results for the design, construction and operation of facilities in areas with slope processes. Bulletin of the Tomsk Polytechnic University. Geo Assets engine ering, 2017, vol. 328, no. 11, pp. 111-125. In Rus.

7. Vodny kadastr SSSR. Mnogoletnie dannye o rezhime poverkhnost nykh vod sushi [Water cadastre of the USSR. Long-term data on the surface water regime]. Ed. by Zh.A. Chernyshova. Leningrad, Gidrometizdat Publ., 1987. Vol. 1, 228 p.

8. Geologiya SSSR. T. XXXIII. Ostrov Sakhalin [Geology of the USSR. Vol. XXXIII. Sakhalin island]. Ed. by A.V. Sidorenko. Moscow, Nedra Publ., 1970. 431 p.
9. Gidrogeologiya SSSR. T. XXIV. Ostrov Sakhalin [Hydrogeology of the USSR. V. XXIV. Sakhalin island]. Ed. by A.V. Sidorenko. Moscow, Nedra Publ., 1972. 344 p.

10. Melkiy V.A., Ilin V.V., Pishchalnik V.M., Sakharov V.A. Results of studies of the natural conditions and engineering-geological structure of the Bolshaya Aleksandrovka river valley (Sakhalin Island). Bulletin of the Tomsk Polytechnic University. Geo Assets engineering, 2015, vol. 326, no. 11, pp. 6-20. In Rus.

11. Nauchno-prikladnoy spravochnik po klimatu SSSR. Mnogoletnie dannye. Sakhalinskaya oblast [Applied reference book on climate of the USSR. Long-term data. Sakhalin region]. Ed. by E.P. Borisenkov. Leningrad, Gidrometeoizdat Publ., 1990. Ser. 3, P. 1-6, Iss. $34,351 \mathrm{p}$.

12. Dugdale S.J., Hannah D.M., Malcolm I.A. River temperature modelling: a review of process-based approaches and future directions. Earth-Science Reviews, 2017, vol. 175, pp. 97-113.

13. Evenstar L.A., Mather A.E., Hartley A.J., Stuart F.M., Cooper F.J. Geomorphology on geologic timescales: Evolution of the late Cenozoic Pacific paleosurface in Northern Chile and Southern Peru. Earth-Science Review, 2017, vol. 171, pp. 1-127.

14. Roy S., Baruah A., Misra S., Mandal N. Effects of bedrock anisotropy on hillslope failure in the Darjeeling-Sikkim Himalaya: an insight from physical and numerical models. Landslides, 2015, vol. 12 (5), pp. 927-941.

15. Stewart L.S., Lewis D. Communicating contested geoscience to the public: Moving from «matters of fact» to «matters of concern». Earth-Science Reviews, 2017, vol. 174, pp. 122-133.

16. Dudler I.V., Khayme N.M., Lyarskiy S.P. Engineering survey methodology for highly hazardous, technically complex and unique objects. Geoekologiya. Inzhenernaya geologiya. Gidrogeologiya. Geokriologiya, 2013, vol. 2, pp. 115-129. In Rus. 
17. Semikina S.S., Sotnikov P.V. Assessment of landslide hazard of coastal slopes in the territory of the city of Barnaul. Bulletin of the Tomsk Polytechnic University. Geo Assets engineering, 2017, vol. 328 , no. 7, pp. 67-75. In Rus.

18. Strokova L.A. Methods of estimating surface settlement during driving of urban tunnels. Soil Mechanics and Foundation Engineering, 2010, vol. 47, no. 3, pp. 92-95.

19. Strokova L.A., Ermolaeva A.V., Golubeva V.V. The Investigation of Dangerous Geological Processes Resulting In Land Subsidence
While Designing the Main Gas Pipeline in South Yakutia. IOP Conference Series: Earth and Environmental Science, 2016, no. $43,6 \mathrm{p}$.

20. Zogning A., Ngouanet C., Tiafack 0. The catastrophic geomorphological processes in humid tropical Africa: A case study of the recent landslide disasters in Cameroon. Sedimentary Geology, 2007, vol. 199, pp. 13-27.

\section{Information about the authors}

Valeriy A. Sakharov, Cand. Sc., head of the laboratory, Sakhalin State University.

Vladimir V. Ilin, senior lector, Sakhalin State University. 